\title{
Everything in moderation, including vision
}

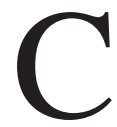

all it a victory for incrementalism. In the run-up to the release of the federal government's fiscal 2012/13 budget, Prime Minister Stephen Harper and Conservative spinmasters billed the blueprint as "transformative," while floating trial balloons hinting at severe cuts and years of dire austerity.

The reality, though, when Finance Minister Jim Flaherty cracked the seal on the blueprint, Jobs Growth and LongTerm Prosperity, was a plan that seemed designed to prove that the budgets delivered under a Conservative majority government are nowhere near as frightening as feared.

Overall program spending for 2012/13 will rise \$3.2 billion to \$276.1 billion, with the federal government's deficit dropping $\$ 3.8$ billion to $\$ 21.1$ billion. That will increase the national debt load to $\$ 602.4$ billion, or $34.4 \%$ of the gross domestic product (www.budget .gc.ca/2012/plan/pdf/Plan2012-eng.pdf).

The government's ballyhooed review of departmental spending will result in an overall $6.9 \%$ reduction in the departments that were subject to the exercise, including \$309.9 million in Health Canada's budget by fiscal 2014/15. For the coming fiscal year, though, the blow is a more modest $\$ 111.7$ million, with the bulk of reduction to be achieved through the consolidation of administration operations, colocation and "organizational simplification" (www.cmaj.ca /lookup/doi/10.1503/cmaj.109-4175).

And in several cases, a departmental or agency cut is offset by an injection of new funds for a targeted purpose, so the effect is often a wash. For example, while the Canadian Institutes of Health Research (CIHR) budget will be reduced $\$ 15$ million in 2012/13 as a result of the spending review exercise, the granting council received $\$ 15$ million per year to support its Strategy for Patient-Oriented Research (www.cihr-irsc.gc.ca/e/41204 .html and www.cmaj.ca/lookup/doi/10 .1503/cmaj.109-4161).

Flaherty lauded the government's

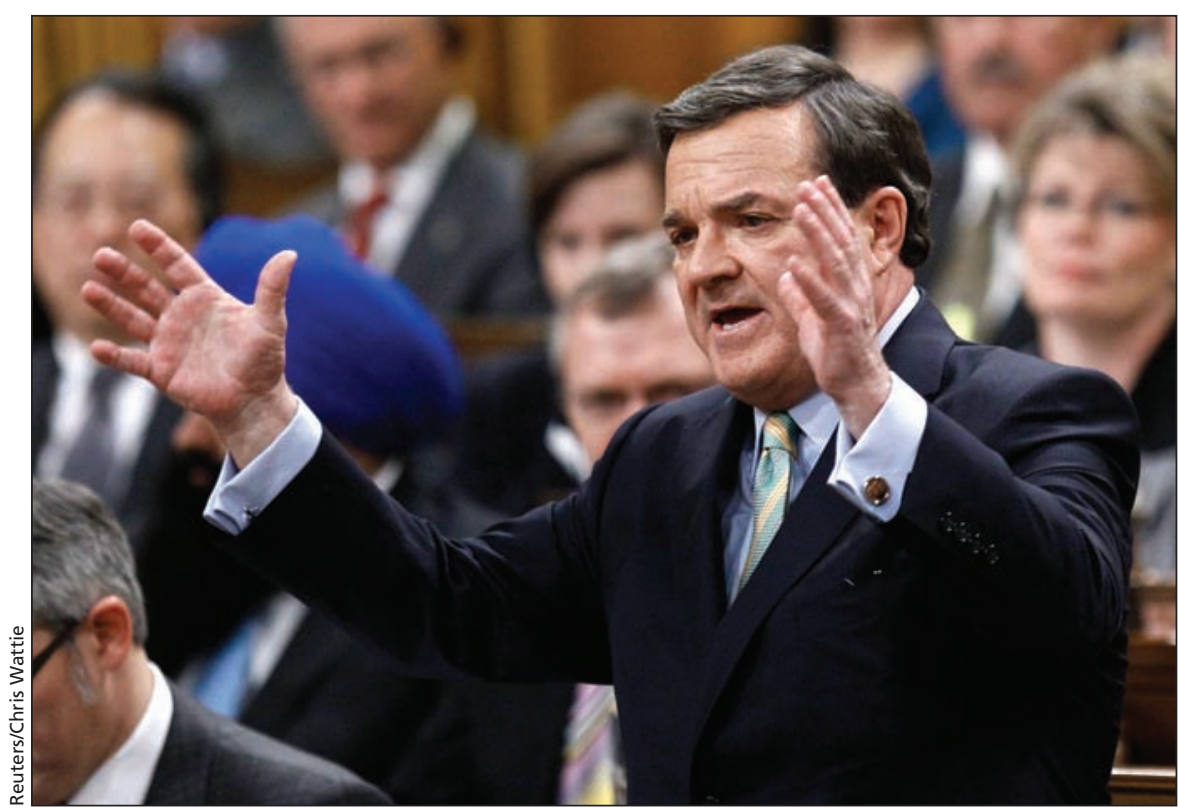

Canadian Finance Minister Jim Flaherty debates his fiscal 2012/13 budget in the House of Commons on Mar. 29, 2012.

incremental, moderate approach to austerity. "Because of our government's responsible choices, we can eliminate the deficit through common-sense, moderate restraint," he said in his budget speech (www.budget.gc.ca/2012/rd -dc/speech-eng.pdf). "We have no need to resort to the drastic cuts being forced upon some other developed countries today. We have no need to undertake the radical austerity measures imposed by the federal government in the 1990s. In fact, our government will return to balanced budgets, while continuing sustainable increases in transfers for social programs. The savings we have identified are moderate. They will amount to less than 2 per cent of federal program spending overall."

But that approach disappointed the health community.

"The verdict is no clear vision on transforming health care, which is a shame. It was an opportunity," says Canadian Medical Association President Dr. John Haggie.

"The greatest enemy, I think, to the future of health care in Canada is government complacency at the federal level. That is the enemy of good health care for Canadians," he adds, noting that there was no mention of health care even for those for whom the federal government has jurisdictional responsibility for providing care, such as Aboriginal peoples, prison inmates and veterans.

As well, Haggie notes, the changes in the old age security eligibility (phasing in the age of retirement to 67 from 65 commencing in 2023), target "an already vulnerable population. My patients have a choice between food, heating and drugs and a lot of them skip their medications because they can't afford it and that's going to get worse. We don't have a pharmaceutical strategy to deal with the fact that chronic disease requires constant or prolonged medication. And that's unfortunate because those two things are going to conspire together to put this group in hospital more frequently than they need to be."

Nor was there anything to deal with ongoing drug shortages, Haggie adds. "The government has all sorts of levers to use and a message I get from patients and my members is that gov- 
ernments should use any and all of them," whether legislative or economic, such as subsidies.

Similarly, Canadian Healthcare Association President Pamela Fralick dubs the blueprint as "not a health budget."

"There's shared leadership in this. We're still looking to the federal government for some leadership on issues, which they're not necessarily embracing at the moment," she says.

The budget cuts are worrisome because so little detail was provided about the precise nature of those reductions, Fralick notes, adding that equally worrisome was the absence of any indication that the federal government plans to pursue the introduction of any manner of accountability mechanisms surrounding health outcomes as part of transfer payments to the provinces for health care.

On that score, the budget did nothing beyond reaffirming Harper's earlier announcement that transfer payments to the provinces for health care will increase by $6 \%$ per year through $2016 / 17$ and then be pegged to a three-year rolling average in the nominal gross domestic product growth rate, with a guaranteed minimum increase of $3 \%$ per year (www.cmaj.ca/lookup/doi/10.1503 /cmaj.109-4109). The Canada Health Transfer will rise to $\$ 28.6$ billion in $2012 / 13$ and $\$ 30.3$ billion in 2013/14 from the current $\$ 27$ billion.

Among other health- and researchrelated measures:

- $\$ 17$ million over two years will be provided to Natural Resources Canada "to further develop alternatives" to nuclear reactor-generated medical isotopes. The department had previously received $\$ 35$ million over two years in 2010 to achieve that objective.

- Atomic Energy of Canada Ltd. will receive $\$ 107$ million over two years "to ensure a secure supply of medical isotopes and maintain safe and reliable operations at the Chalk River Laboratories." The agency had received \$405 million in 2011/12 for the same purpose, as well as to cover financial losses related to the 2007 shutdown of the National Research Universal reactor.

- As with CIHR, the spending review exercise resulted in a \$15-million cut to the budget of the Natural Sciences and Engineering Research Council (NSERC) in 2012/13, and an additional \$15 million in the following fiscal year. The budget of the Social Sciences and Humanities Research Council (SSHRC) was cut $\$ 7$ million for 2012/13 and another \$7 million the following year. But the 2012/13 cuts are offset by the provision of $\$ 37$ million annually (\$15 million to CIHR, \$15 million to NSERC and $\$ 7$ million to SSHRC) in "support of industry-academic research partnership initiatives." The staggered cuts could result in a serious hit to granting councils' base budgets in 2013/14 but Treasury Board and Finance officials, who speak on condition of anonymity during budget background briefings, indicated that the expectations are that the bolstered funding for industry-academic partnerships will be repeated in next year's federal budget, so that council budgets will continue to remain at roughly $\$ 1$ billion apiece for CIHR and NSERC, and about \$651 million for SSHRC. "The net effect is that overall council funding will be unchanged," one Finance official stressed. That's based, though, on the presumption of an increase for 2013/14. About 25\% of the medical and natural sciences budgets, and $45 \%$ of the social sciences budget, represents monies administered by the councils on behalf of the government for special initiatives, such as one to cover the indirect costs of research.

- Genome Canada will receive \$10 million in 2012/13 and \$50 million in 2013/14 to "launch a new applied research competition in the area of human health" and to sustain operating costs at regional genomics centres.

- $\$ 5.2$ million will be provided to support the creation of a Canadian Depression Research and Intervention Network by the Mood Disorders Society of Canada and the Mental Health Commission of Canada. It will connect "over 80 of Canada's brightest depression researchers from across the country. Particular focus will be on suicide prevention and identifying and treating post-traumatic stress disorder. Funding provided in the budget will serve as a catalyst for private and public sector investment."

- $\$ 6.5$ million over three years will be provided to researchers at McMaster University in Hamilton, Ontario to conduct an evaluation of "ways to achieve better health outcomes for patients while also making the health care system more cost-effective, through greater implementation of medical teams."

- Commencing this year, physicians will be included among the "target occupations" in the Pan-Canadian Framework for the Assessment and Recognition of Foreign Qualifications, under which foreign-trained professionals who seek to work in Canada will have their qualifications assessed within a one year period.

- The budget indicated that the government "will continue to partner with the Rick Hansen Institute" to support spinal cord injury research and care. But Finance officials said no dollar figures are attached to the promise. In 2010, the government committed \$13.5 million over three years to the initiative.

- The Canada Foundation for Innovation will receive $\$ 500$ million over five years, commencing in 2014/15, to support research infrastructure projects within the nation's universities. (Through the years, the government has previously allocated $\$ 5$ billion for such infrastructure).

- In what Finance officials called "the first phase of the government's new approach to supporting business innovation," revisions were made to the Scientific Research and Experimental Development program which provides tax incentives to industry to conduct research. The most significant changes are the elimination of capital expenditures, such as buildings, from eligibility for the tax credit, as well as reduction in the tax credit rate to $15 \%$ from 20\%, effective Jan. 1, 2014.

- The National Research Council will continue to be restructured as a tool box for industry, receiving an additional \$67 million this year to support its "refocusing on business-led, indus- 
try-relevant research." The council will also see its Industrial Research Assistance Program contributions budget, which provides extramural grants to businesses to develop products, double to $\$ 220$ million per year. The combined increases will hike the National Research Council's overall budget to $\$ 700.5$ million in 2012/13.

- In a continuation of previous grants, the Canadian Institute for Advanced Research will receive $\$ 10$ million over two years in support of its studies.

- $\$ 12$ million per year will be set aside to make the Business-Led Networks of Centres of Excellence program "permanent." In the original competition to create such networks, the four winners included the Québec Consortium for Drug DiscoveryCQDM (Nuns' Island, Quebec), which aimed to "accelerate the drug discovery process and to develop safer and more effective drugs."

- Canada's Advanced Research and Innovation Network received $\$ 40$ million over two years for ongoing development of an ultra highspeed research network.

- Revisions in goods and services tax/harmonized (GST/HST) sales tax law will see pharmacists' profes- sional services, such as ordering and interpreting lab tests or administering vaccinations, become exempt from GST/HST. (Their drug dispensing services have always been exempt). As well, there will be an expansion of the list of health care professionals (to include, for example, nurses) who can order medical and assistive devices without having to pay the tax, while individuals will be allowed to claim a GST/HST tax credit for blood coagulation monitors. - Wayne Kondro, CMAJ

CMAJ 2012. DOI:10.1503/cmaj.109-4174 